\title{
Bacterial etiology of sputum from tuberculosis suspected patients and antibiogram of the isolates
}

\author{
Ramesh Sharma Regmi ${ }^{1}$, Sujan Khadka ${ }^{1,2,4}$, Sanjeep Sapkota ${ }^{1,3,4}$, Sanjib Adhikari ${ }^{*}$ (D, Khuma Kumari Dhakal ${ }^{1}$, \\ Bishnu Dhakal ${ }^{1}$, Bandana Lamsal ${ }^{1}$ and Sarad Chandra Kafle ${ }^{1}$
}

\begin{abstract}
Objective: The current study aims to explore the bacteriology of sputum of tuberculosis (TB) suspected patients. A cross-sectional study was carried out in the sputum samples of 150 TB suspected patients visiting District Public Health Office, Bharatpur, Nepal. The samples were subjected to cultural, microscopic and biochemical analyses for the identification of the isolates. In addition, antibiotic susceptibility tests were carried out with a special focus on ESBL and MBL production following Clinical and Laboratory Standard Institute guidelines.

Results: Bacterial growth was recovered in 47\% (71/150) of the TB suspected patients of which $12.66 \%(19 / 150)$ had pulmonary TB infection. Streptococcus spp. (9\%) and Pseudomonas aeruginosa (9\%) were the most frequently isolated bacteria. Enterobacteriaceae accounted for $35 \%$ of the total isolates. Occurrence of bacterial pathogens was more in males (69\%) than in females (31\%). The incidence of bacterial pathogen was seen associated with gender of the patients and with the TB infection $(p<0.05)$ but independent with age of the patients and HIV infection $(p>0.05)$. Tetracycline was effective against Streptococcus spp. whereas gentamicin was effective against Bacillus species. Imipenem and co-trimoxazole were effective drugs for Gram-negative isolates. Among 83 isolates, 35 were multi-drug resistant, 9 were ESBL producers and 4 were MBL producers.
\end{abstract}

Keywords: Tuberculosis, Respiratory tract infection, MDR, Sputum

\section{Introduction}

Respiratory Tract Infections (RTIs) are the most frequently reported among human infections, out of which Lower Respiratory Tract Infections (LRTIs) account for almost 90\% [1]. Upper Respiratory Tract Infections (URTIs) are commonly caused by viruses than bacteria and fungi but LRTIs are more commonly caused by bacteria and less by fungi and viruses. These diseases directly result in about 7 million deaths annually [2]. The HIV pandemic has even worsened morbidity and

\footnotetext{
*Correspondence: sanadh26@gmail.com

${ }^{1}$ Department of Microbiology, Birendra Multiple Campus, Tribhuvan

University, Bharatpur, Chitwan 44200, Nepal

Full list of author information is available at the end of the article
}

mortality due to LRTIs which causes about $70 \%$ of illnesses in AIDS patients [3]. To differentiate Tuberculosis (TB) from other LRTIs such as bacterial pneumonia is an important clinical challenge in developing countries, and failure to differentiate TB from other LRTIs may result in poorer health outcomes which may lead in high mortality rate [4]. Tuberculosis is the most feared health issue in developing countries like Nepal. Emergence of bacterial coinfections along with the development of antimicrobial resistance complicates the TB-treatment process [5].

Several studies carried out world-wide report that the potent pathogens of RTIs are Streptococcus pneumoniae, Haemophilus influenzae, Klebsiella pneumoniae, Pseudomonas aeruginosa, Escherichia coli, Staphylococcus aureus, Bacillus spp., Moraxella 
catarrhalis, Streptococcus pyogenes and some other enteric Gram-negative rods such as Salmonella choleraesuis, Citrobacter koseri $[6,7]$. Most of these bacteria are normal flora of the human respiratory tract. So it is clear that most of the time, the infection is initiated by normal flora and secondary infection from other invader bacteria [8].

Gram-negative bacteria, especially Enterobacteriaceae are increasing their antibiotic resistance ability [9]. Gram-positive cocci such as S. aureus and Streptococcus spp. are also evolving as multi-drug resistant (MDR) [10]. To the best of our knowledge, no any attempts have been made yet exploring the bacterial composition of sputum of TB suspected patients in Nepal. Hence, this study was designed to explore the bacteriological spectrum of sputum from the patients suspected of tuberculosis and determine the antibiotic susceptibility pattern of the isolates.

\section{Main text}

\section{Study design, area and sample population}

This was a descriptive cross-sectional study enrolling 150 TB suspected patients who visited District Public Health Laboratory (DPHO), Bharatpur, Chitwan over 2 months from January to February, 2020. The patients were asked to collect early morning sputum sample in a clean dry and leak-proof container and bring it cautiously to DPHO laboratory.

\section{Sample collection and transport}

Immediately after collecting the sputum, each sample was observed microscopically for the presence of AFB bacilli by Ziehl-Neelsen staining at DPHO laboratory. The samples were transported aseptically to the Microbiology laboratory of Birendra Multiple Campus for bacteriological investigations. A little of each AFB positive sample was left at the DPHO laboratory for further analysis by Genexpert method.

\section{Culture and identification of the isolates}

The methodology was followed according to a similar study done by Ngekeng [6]. A loopful of the uncentrifuged sample was streaked over Chocolate agar, Blood agar, MacConkey agar and XLD agar (Hi-Media, India) under laminar airflow conditions. Blood agar was incubated at anaerobic condition and Chocolate agar, MacConkey agar and XLD agar were incubated at the aerobic condition for $24 \mathrm{~h}$ at $37{ }^{\circ} \mathrm{C}$. Identification of bacterial isolates was done based on their morphological and biochemical characteristics [11].

\section{Antibiotic susceptibility testing}

Antibiotic Susceptibility Test was done by modified Kirby Bauer's disc diffusion method following CLSI guidelines (2016) [12]. Altogether, 17 different commonly used antibiotics procured from Hi-Media, India were used for testing. In case of Bacillus spp., AST was performed as suggested by Charteris et al. [13].

\section{Screening of ESBL and MBL producers}

Primary screening of ESBL producers was done by using ceftazidime (CAZ) $(30 \mu \mathrm{g})$ and cefotaxime (CTX) $(30 \mu \mathrm{g})$ disks (Hi-Media, India). If the zone of inhibition was $22 \mathrm{~mm}$ for CAZ and/or $27 \mathrm{~mm}$ for CTX, the isolate was considered a potential ESBL-producer as recommended by NCCLS [14]. Combination disk method [15] was used to confirm ESBL-producing isolates in which CTX and CAZ $(30 \mu \mathrm{g})$, alone and in combination with clavulanic acid (CA) $(10 \mu \mathrm{g})$ were used. An increase in ZOI of $5 \mathrm{~mm}$ for either antimicrobial agent tested in combination with $C A$ versus its zone when tested alone confirmed ESBL [12]. Imipenem resistant Gramnegative isolates were selected for the further detection of MBL production by disc potentiation method using imipenem $(10 \mu \mathrm{g})$ and meropenem $(10 \mu \mathrm{g})$ with and without EDTA $(1 \mu \mathrm{g})$ as previously described [24].

\section{Quality control}

Each batch of media and reagents was subjected to sterility and performance testing. During antibiotic susceptibility test, quality control was done using the control strains of E. coli ATCC 25922.

\section{Data management and statistical analysis}

All the raw data obtained in this study were tabulated in SPSS V.20 and Chi-square test was performed. $\mathrm{P} \leq 0.05$ was assigned as significant.

\section{Results}

\section{Distribution of bacteria in sputum}

Among the 150 sputum samples, only 71 (47.33\%) showed the bacterial growth, out of which 61 (85.92\%) had monomicrobial growth and 10 (14.09\%) had polymicrobial growth. The most common bacteria were Streptococcus spp. and Pseudomonas aeruginosa, both isolated in $14(9.33 \%)$ samples. Enterobacteriaceae isolates were obtained in 21 instances, among which $K$. pneumoniae was predominant 13 (8.67\%) (Fig. 1).

\section{Association of different variables with bacterial isolation}

Among 150 study participants, only 5 (3.33\%) people were HIV-infected of which $4(80.00 \%)$ showed the bacterial growth. The incidence of bacterial growth 


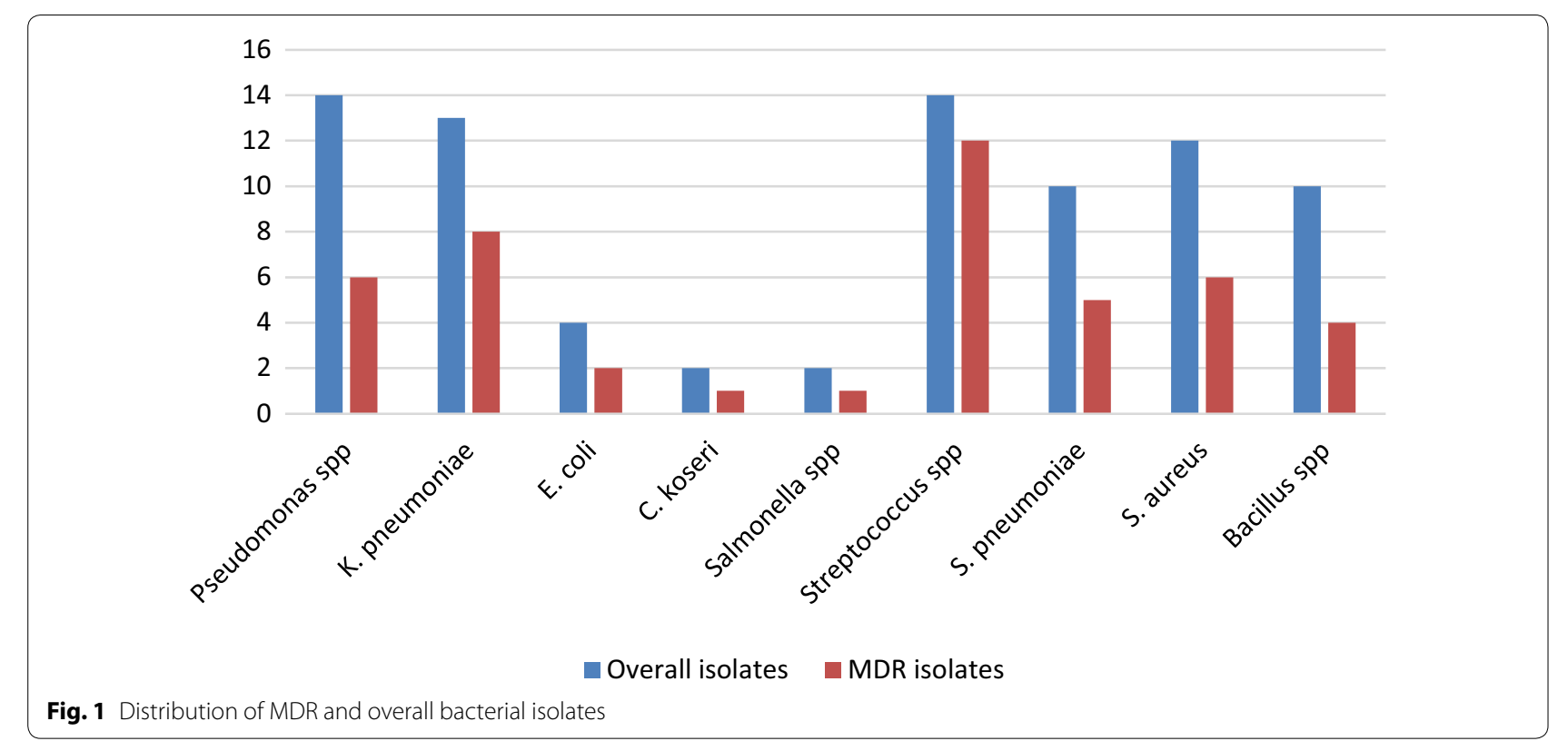

was not found associated with HIV infection ( $p>0.05$ ). Gender-wise, $54.44 \%$ of growth was recovered from males and $36.67 \%$ from females and recovery of bacteria in sputum sample was found associated with gender $(\mathrm{p}<0.05)$. Higher prevalence of LRTIs was found in the age group 31-45 and 46-60 accounting for 14 (56.00\%) and $29(55.76 \%)$ of growth respectively. However, no statistical association was observed between bacterial incidence with the age group ( $\mathrm{p}>0.05)$. Among $150 \mathrm{~TB}$ suspected patients, only $12.67 \%$ were confirmed to have tuberculosis of which 18 (94.74\%) showed the growth of bacteria. A very high degree of association was noted between the incidence of bacterial pathogens and tuberculosis infection $(\mathrm{p}<0.05)$. Current smokers were found to be more vulnerable to bacterial infection as compared to non-smokers and past smokers as $65.79 \%$ isolates were recovered from the current smokers. A strong association was observed statistically between the smoking habit and bacterial growth $(\mathrm{p}<0.05)$. Habit of alcohol consumption was also noted to contribute significantly in bacterial infection as $78.57 \%$ alcohol consumers showed growth of bacteria $(\mathrm{p}<0.05)$ (Table1).

\section{Antibiotic susceptibility pattern of the isolates}

Antibiogram of the Streptococcus spp. showed tetracycline was most effective drug with $86.33 \%$ sensitivity, whereas gentamicin was least effective with $14.30 \%$ sensitivity. All Enterobacteriaceae isolates were resistant to amoxicillin/clavulanic acid whereas sensitive to cotrimoxazole. $P$. aeruginosa was sensitive to some of the second-line antibiotics whereas amikacin was completely
Table 1 Distribution of bacterial growth with various attributes

\begin{tabular}{lclll}
\hline Attributes & Sample size & $\begin{array}{l}\text { Growth rate } \\
(\%)\end{array}$ & $\begin{array}{l}\text { Odds ratio (95\% } \\
\text { Cl) }\end{array}$ & p-value \\
\hline $\begin{array}{l}\text { Gender } \\
\text { Male }\end{array}$ & 90 & 54.44 & $2.06(1.06-4.03)$ & 0.033 \\
$\begin{array}{l}\text { Female } \\
\text { Age group }\end{array}$ & 60 & 36.66 & 1 & \\
0-15 & 9 & & & \\
16-30 & 29 & 37.93 & $0.76(0.17-3.47)$ & 0.727 \\
31-45 & 25 & 56.00 & $1.59(0.34-7.37)$ & 0.553 \\
$46-60$ & 52 & 55.76 & $1.58(0.38-6.54)$ & 0.531 \\
60+ & 35 & 37.14 & $0.74(0.17-3.25)$ & 0.689 \\
Smoking & & & & \\
Yes & 38 & 65.79 & $2.65(1.16-6.04)$ & 0.020 \\
No & 69 & 42.03 & 1 & \\
In past & 43 & 39.53 & $0.9(0.42-1.96)$ & 0.794 \\
Alcohol consumption & & & \\
Yes & 28 & 78.57 & $5.84(2.14-15.97)$ & 0.000 \\
No & 83 & 38.55 & 1 & \\
In past & 39 & 43.59 & $1.23(0.57-2.67)$ & 0.597 \\
TB infection & & & & \\
Yes & 19 & 94.74 & $26.49(3.43-204.46)$ & 0.001 \\
No & 131 & 40.46 & 1 & \\
HIV infection & & & & \\
Yes & 5 & 80.00 & $4.66(0.51-42.68)$ & 0.174 \\
No & 145 & 46.21 & 1 & \\
\hline & & & & \\
\hline
\end{tabular}

resisted by it (Additional file 1: Tables S1 and S2). Among total 81 bacterial isolates, 45 were multi-drug resistant (MDR). Streptococcus spp. was predominant (26.67\%) 
among the MDR isolates (Fig. 1). To confirm ESBL producers, 14 presumed ESBL producing isolates were tested among which 9 (25.71\%) isolates were confirmed ESBL producers, K. pneumoniae 4 (44.44\%) being the predominant one. On performing combined disk test of 10 presumptive MBL isolates, only 4 (40.00\%) were confirmed as MBL producers of which 2 isolates were $P$. aeruginosa and 1 each of K. pneumoniae and E. coli (Table 2).

\section{Discussion}

This study documented bacterial growth in the sputum of $47.33 \%$ (71/150) tuberculosis-suspected individuals. A Cambodian study also revealed similar result with $43.79 \%$ bacterial growth [4]. On the other hand, report from a Nigerian study showed a growth rate of around $61.37 \%$ [6]. Such a high degree of variation may be due to the different methods employed for the collection and processing of the samples in different places. In the current study, $P$. aeruginosa was the most predominant bacterial isolate recovered in $9.33 \%$ of the total sample. A similar result was found in a research done in Pakistan, where the prevalence of $P$. aeruginosa was11.96\% [16]. The frequent incidence of $P$. aeruginosa in the sputum may be owing to their ability to colonize a wide range of ecological niches, such as air polluting agents, animal hosts and humans [17]. S. pneumoniae was isolated in $6.67 \% \mathrm{spu}-$ tum samples in our study, but in most of the other similar world-wide studies, S. pneumoniae has been reported as the chief isolate $[6,18,19]$. In the present study, the prevalence of K. pneumoniae was $8.67 \%$ in the sputum samples. This rate is almost similar to the study conducted by Hasan et al. who observed a $10.8 \%$ prevalence of $K$. pneumoniae [20]. Prevalence of Staphylococcus aureus was $8.00 \%$ in this study, similar to Ngekeng's study where it was 6.5\% [6]. Incidence of Streptococcus spp., S. aureus and $K$. pneumoniae may be due to their distribution in the respiratory tract where they remain as opportunistic pathogens and may infect when patient's immune system is compromised. We observed a prevalence of $6.67 \%$ for
Bacillus spp. which is exactly similar to the study carried out in Iraq [20].

Prevalence of LRTIs was found greater in male (54.44\%) than in female (36.67\%). A similar study in Nigeria showed LRTIs was $54.80 \%$ in male and $67.10 \%$ in female [6]. Gender has varied impact on bacterial incidence as some studies show higher infection in females [19] while others show more in males [18]. Higher growth reported among men in our study might be due to lifestyle factors like smoking and alcohol consumption [6]. Higher prevalence of infection was seen in the age group 31-45 (56.00\%) and $46-60(55.76 \%)$. A similar study by Attia et al. showed the age group 38-65 (53.00\%) as the most susceptible for LRTIs [4]. Age group of 46-60 are under more threats of being infected as people in this age group have declined level of immunity and their exposure to the environment is high [21]. In our study, $12.67 \%$ of the suspected patients were confirmed to have TB. This rate is similar to the study carried by Ngekeng et al. where it was $13.79 \%$ [6]. Tuberculosis infection was significantly associated with bacterial co-infection $(\mathrm{p}<0.05)$. As immunity decreases during active $\mathrm{TB}$, bacteria attack the immunecompromised person more easily as compared to healthier person [22]. In the current study, only 5 (3.33\%) people were HIV-infected patients and no any association was observed between having HIV with bacterial incidence $(\mathrm{p}>0.05)$. This study accounted $65.79 \%$ bacterial growth from the smokers. This rate is higher than the study carried out by Ngekeng where it was $61.10 \%$ [6]. In a study, Attia and his colleagues found the staggering rate of $81.81 \%$ where a significant association between smoking and bacterial growth was not noted [4]. The rate of bacterial growth among alcohol consumers was $78.57 \%$ in this study, which is $53.9 \%$ in a study carried out in Nigeria [6]. Higher prevalence of bacterial growth in those who were habitual to smoking and alcoholism may be because smoking and alcoholism usually increase risk to lower respiratory tract infections by diminishing mucosal immunity [18].

Table 2 Frequency of ESBL and MBL isolates

\begin{tabular}{lllll}
\hline Organisms & ESBL & & MBL & \\
\cline { 2 - 3 } & Presumptive & $\begin{array}{l}\text { Confirmatory (combination disk } \\
\text { method) }\end{array}$ & Presumptive & $\begin{array}{l}\text { Confirmatory } \\
\text { (combined disk } \\
\text { test) }\end{array}$ \\
\hline P. aeruginosa & 4 & $2(50.00 \%)$ & 5 & $2(40.00 \%)$ \\
K. pneumoniae & 7 & $4(57.14 \%)$ & 3 & $1(33.33 \%)$ \\
E. coli & 2 & $2(100.00 \%)$ & 2 & $1(50.00 \%)$ \\
Salmonella spp. & 1 & $1(100.00 \%)$ & 0 & 0 \\
Total & 14 & $9(64.29 \%)$ & 10 & $4(40.00 \%)$ \\
\hline
\end{tabular}


The present study documented $55.56 \%$ MDR isolates which is higher than a study carried out in Kathmandu (47.57\%) [23]. Another study in the same city also showed similar prevalence of MDR isolates (57.50\%) [24]. Besides, $26.00 \%$ of Gram-negative isolates were ESBL producers in this study, K. pneumoniae being the top contributor. This rate is similar to the one carried out by Pokhrel and his colleagues where the rate was $24.27 \%$ with the same organism being dominant. This study also documented $11.43 \%$ of Gram-negative isolates as MBL producers. A study carried out in LRTIs patients in Nepal Medical College revealed 5.80\% isolates were MBL producers [24]. Another study in Nigeria accounted 4.70\% Gram-negative isolates as MBL producer [25].

\section{Conclusions}

The current study reveals a bacterial prevalence of 47.33\% from the sputum of TB-suspected patients. Out of 150 study subjects, $12.66 \%$ (19/150) had pulmonary tuberculosis. Discovery of multidrug resistant bacteria including EBL and MBL producers in the sputum of patients with TB and LRTIs is worrisome and concerned authorities should be more alert to abate their incidence and dissemination.

\section{Limitations}

The present study doesn't indicate whether the TB suspected patients had some other LRTIs such as pneumonia. Also, it does not include other important LRTIs causing bacteria such as $H$. influenzae and M. catarrhalis.

\section{Supplementary information}

Supplementary information accompanies this paper at https://doi. org/10.1186/s13104-020-05369-8.

Additional file 1: Table S1. Antibiotic susceptibility pattern of Grampositive isolates. Table S2. Antibiotic susceptibilty pattern of Gramnegative isolates.

\section{Abbreviations}

TB: Tuberculosis; ESBL: Extended spectrum beta-lactamase; MBL: Metallo betalactamase; MDR: Multidrug resistant; AST: Antibiotic susceptibility test; CLSI: Clinical and laboratory standards institute; ZOI: Zone of inhibition.

\section{Acknowledgements}

We thank all the patients who provided us with sputum sample for this study. We would like to thank all the staffs of DPHO, Bharatpur. We are also grateful to all the staffs of Microbiology Laboratory of Birendra Multiple Campus, Bharatpur, Chitwan.

\section{Authors' contributions}

RSR and SA conceived the concept and design of this study. RSR, BD, BL and KKD performed experimental work. RSR, SS, SA, SK and SCK analyzed the data and prepared the final draft of the manuscript. All authors read and approved the final manuscript.
Funding

No specific funding was available for this study.

\section{Availability of data and materials}

All the data obtained during this study are available within the article.

\section{Ethics approval and consent to participate}

As the sampling process involves human volunteers, ethical consent was required prior to executing the research work. Ethical clearance was taken from the National Health Research Council (NHRC) (Ref No. 1464). Patients were recruited into after obtaining written informed consent.

\section{Consent of publication}

Not applicable.

\section{Competing interests}

The authors declare that they have no competing interests.

\section{Author details}

${ }^{1}$ Department of Microbiology, Birendra Multiple Campus, Tribhuvan University, Bharatpur, Chitwan 44200, Nepal. ${ }^{2}$ State Key Laboratory of Environmental Aquatic Chemistry, Research Center for Eco-Environmental Sciences, Chinese Academy of Sciences, Beijing 100085, China. ${ }^{3}$ State Key Laboratory of Respiratory Disease, Guangzhou Institutes of Biomedicine and Health, Chinese Academy of Sciences, Guangzhou 510530, China. ${ }^{4}$ University of Chinese Academy of Sciences, Beijing 100049, China.

Received: 16 June 2020 Accepted: 31 October 2020

Published online: 10 November 2020

\section{References}

1. Thomas M, Bomar P, Koutsothanasis GA. Upper respiratory tract infection. Treasure Island: StatPearls Publishing; 2019. https://www.ncbi.nlm.nih. gov/books/NBK532961/.

2. Akan OA, Ahmed K, Nagatake T, Ozyilmaz E, Gulhan M. Major bacteria of community-acquired respiratory tract infections in Turkey. Jpn J Infect Dis. 2005:58:50-2.

3. Walker P, White D. Pulmonary disease. Med Clin North Am. 1996;80:1337-62.

4. Attia EF, Pho Y, Nhem S, Sok C, By B, Phann D, et al. Tuberculosis and other bacterial co-infection in Cambodia: a single center retrospective crosssectional study. BMC Pulm Med. 2019;19:1-7.

5. Langbang A, Deka N, Rahman H, Kalita D. A study on bacterial pathogens causing secondary infections in patients suffering from tuberculosis and their pattern of antibiotic sensitivity. Int J Curr Microbiol Appl Sci. 2016;5:197-203.

6. Ngekeng S, Pokam B, Meriki H, Njunda A, Assob J, Ane-Anyangwe I. High prevalence of bacterial pathogens in sputum of tuberculosis suspected patients in Buea. Br Microbiol Res J. 2015:11:1-8.

7. Iliyasu G, Mohammad AB, Yakasai AM, Dayyab FM, Oduh J, Habib AG. Gram-negative bacilli are a major cause of secondary pneumonia in patients with pulmonary tuberculosis: evidence from a cross-sectional study in a tertiary hospital in Nigeria. Trans R Soc Trop Med Hyg. 2018;112:252-4.

8. Davis CP. Normal flora. In: Medical microbiology. Edinburgh: Elsevier; 1996.

9. Adhikari S, Khadka S, Rana JC, Baniya S, Poudel S, Chapagain A, et al. Prevalence of $\beta$-lactamase producing carbapenem-resistant enterobacteriaceae among the patients attending Bharatpur Hospital. Biosci Discov. 2019:10:64-71.

10. Bertrand X, Hocquet D. Antibiotic drug resistance: Causes and solutions. EJHP Pract. 2011;17:58-9.

11. Forbes BA, Sahm DF, Weissfeld AS. Diagnostic microbiology. St Louis: Mosby; 2007

12. Clinical Laboratory Standards Institute (CLSI). Performance standards for antimicrobial susceptibility testing. In: 24th informational Suppl (M100-S28) Wayne. 2016. 
13. Hana J, Chena D, Lic S, Lia X, Zhoud WW, Zhangb B, et al. Antibiotic susceptibility of potentially probiotic Lactobacillus strains. Ital J Food Sci. 2015;27:282-9.

14. Parajuli NP, Maharjan P, Joshi G, Khanal PR. Emerging perils of extended spectrum $\beta$-lactamase producing Enterobacteriaceae clinical isolates in a teaching hospital of Nepal. Biomed Res Int. 2016. https://doi. org/10.1155/2016/1782835

15. Samaha-Kfoury JN, Araj GF. Recent developments in lactamases and extended spectrum lactamases. BMJ. 2003;327:1209-13.

16. Nazi SA, Campus G. Prevalence and antibiogram pattern of pseudomonas species causing secondary infections among patients of pulmonary tuberculosis. Intl Chem Pharm Med J. 2005;2:231-7.

17. Chevalier S, Bouffartigues E, Bodilis J, Maillot O, Lesouhaitier O, Feuilloley MGJ, et al. Structure, function and regulation of Pseudomonas aeruginosa porins. FEMS Microbiol Rev. 2017;41:698-722

18. Akingbade OA, Ogiogwa II, Okerentugba PO, Innocent-Adiele H, Nwanze J, Okonko I, et al. Prevalence and antibiotic susceptibility pattern of bacterial agents involved in lower respiratory tract infections in Abeokuta, Ogun State, Nigeria. Rep Opin. 2012;4:25-30.

19. Egbagbe E, Mordi R. Aetiology of lower respiratory tract infection in Benin City, Nigeria. J Med Biomed Res. 2009;5:22-7.

20. Hasan AZ, Al-sulami A, Al-taee A. Gram positive and gram negative bacteria from sputum of clinically tuberculosis suspected patients. Int J Curr Res. 2015;7:14289-91.
21. Egbe CA, Ndiokwere C, Omoregie R. Microbiology of lower respiratory tract infections in Benin city, Nigeria. Malays J Med Sci. 2011;18:27-31.

22. Sia JK, Rengarajan J. Immunology of Mycobacterium tuberculosis infections Jonathan. Microbiol Spectr. 2019;176:139-48.

23. Pokhrel BM, Koirala J, Mishra SK, Dahal RK, Khadga P, Tuladhar NR. Multidrug resistance and extended spectrum betalactamase producing strains causing lower respiratory tract and urinary tract infection. J Inst Med. 2006;28:19-27

24. Thapa P, Bhandari D, Shrestha D, Parajuli H, Chaudhary P, Amatya J, et al. A hospital based surveillance of metallo-beta-lactamase producing gram negative bacteria in Nepal by imipenem-EDTA disk method. BMC Res Notes. 2017;10:1-6.

25. Ehondor TO, Ogefere HO, Ibadin EE. Detection of metallo- $\beta$-lactamaseproducing Gram-negative bacterial isolates from patients with lower respiratory tract infections in a Tertiary Hospital in Benin City, Nigeria. J Med Lab Sci. 2019;29:21-8.

\section{Publisher's Note}

Springer Nature remains neutral with regard to jurisdictional claims in published maps and institutional affiliations.
Ready to submit your research? Choose BMC and benefit from:

- fast, convenient online submission

- thorough peer review by experienced researchers in your field

- rapid publication on acceptance

- support for research data, including large and complex data types

- gold Open Access which fosters wider collaboration and increased citations

- maximum visibility for your research: over $100 \mathrm{M}$ website views per year

At BMC, research is always in progress.

Learn more biomedcentral.com/submissions 